\title{
Perspectives on Disability Disclosure: The Importance of Employer Practices and Workplace Climate
}

\author{
Sarah von Schrader • Valerie Malzer • Susanne Bruyère
}

Published online: 20 July 2013

(C) The Author(s) 2013. This article is published with open access at Springerlink.com

\begin{abstract}
Disclosing a disability to a potential or current employer is a very personal decision, with potentially far-reaching consequences for both the employer and employee. Disability disclosure can assure that employees receive appropriate workplace accommodations, and can help employers respond more effectively to diversity and inclusion initiatives aimed at increasing the hiring and retention of individuals with disabilities. However, disclosure may also result in negative employment consequences for employees, such as lowered supervisor expectations, isolation from co-workers, and increased likelihood of termination. Given demographic trends related to disability in the labor force and recent initiatives to increase the employment of individuals with disabilities, it is increasingly important that employers create an environment that encourages disclosure and reduces the likelihood of negative consequences for employees and applicants who disclose their disabilities. This paper presents the findings of a survey of individuals with disabilities focused on identifying and better understanding the factors that influence the disclosure decision. Results highlight the barriers and facilitators that influence individuals' decision to disclose and the important role that employers, managers, and workplace climate play in the decision. Implications for employer policy and practice are also discussed.
\end{abstract}

Keywords Disclosure $\cdot$ Disability $\cdot$ Self-identification $\cdot$ Employer practices $\cdot$ Inclusion

The authors would like acknowledge the significant contributions of Robin Shaffert and Francesca Mastrangelo of the American Association of People with Disabilities, Crystal Blyler of the Substance Abuse and Mental Health Services Administration, and William Erickson and Sara Van Looy of the Employment and Disability Institute, Cornell University in the design and implementation of this study.

The contents of this paper were developed under grants from the Department of Education, NIDRR grant numbers H133B040013 (Rehabilitation Research and Training Center on Employment Policy and Individuals with Disabilities) and H133B100017 (Rehabilitation Research and Training Center on Employer Practices Related to Employment Outcomes among Individuals with Disabilities). However, those contents do not necessarily represent the policy of the Department of Education, and you should not assume endorsement by the Federal Government.

S. von Schrader $(\bowtie) \cdot$ V. Malzer $\cdot S$. Bruyère Employment and Disability Institute, Cornell University, 201 Dolgen Hall, Ithaca, NY 14850, USA e-mail: sv282@cornell.edu 


\section{Introduction}

\section{Disability in the Workplace}

The Americans with Disabilities Act of 1990a, b (ADA) is a comprehensive federal law protecting the fundamental civil rights of individuals with disabilities. Title I of the ADA specifically prohibits discrimination in employment against qualified individuals with a disability with the goal of providing equal employment opportunities. The ADA has now been in place for more than 20 years, however, the employment rate of people with disabilities has not increased (Bjelland et al. 2011; Weathers and Wittenburg 2009), even as the U.S. workforce has become increasingly diverse with regard to other groups protected under anti-discrimination legislation (e.g., women, minority groups, and older individuals (Toossi 2012)). Currently, employment rates for people with disabilities remain significantly lower than those of non-disabled individuals, with the employment rate for individuals with a disability being $33.4 \%$, compared to $75.6 \%$ for their non-disabled peers (Erickson et al. 2012). There are persistent concerns that disparate treatment by employers may be contributing to this employment gap (Kessler/NOD 2010; Robert and Harlan 2006). For example, employers may be hesitant to hire workers with disabilities because of negative attitudes about disability, perceived lack of skills among people with disabilities, or perceptions that accommodation or other costs are too high (Bruyère et al. 2000; Domzal et al. 2008; Lengnick-Hall et al. 2008).

Increasing employer literacy about disability issues is critically important not only because of regulatory requirements such as the ADA, but also because changing demographics and new federal initiatives are requiring increased attention to improving disability nondiscrimination policies and practices in their workplaces.

Current Prevalence and Demographic Shifts Individuals with disabilities make up around $5.3 \%$ of the U.S. workforce, according to the American Community Survey (U.S. Census Bureau 2011). This rate of disability in the workforce is likely to increase as the workforce ages. In 1990 , less than $12 \%$ of the workforce was 55 and older; this increased to $20 \%$ in 2010 , and is expected to jump to over $25 \%$ by 2020 (Toossi 2012). The increasing proportion of older people in the workforce heightens the likelihood of more workers with disabilities, as research shows that the incidence and prevalence of disability increases with age (He et al. 2005; Houtenville et al. 2009). In addition, many veterans returning to civilian employment have some level of service-connected disability, often in the form of non-apparent disabilities such as depression, post-traumatic stress disorder and traumatic brain injury (Ramchand et al. 2008; Richardson et al. 2011); and many employers are not prepared to address disclosure issues or successfully accommodate these conditions (Rudstam et al. 2012).

Federal Initiatives In addition to the ADA, many employers are subject to the Rehabilitation Act of 1973, as amended, which requires disability nondiscrimination and affirmative action for federal agency employers (Section 501) and federal contractors and sub-contractors (Section 503). To address the persistent employment gap between people with and without disabilities in these two sectors, two current federal initiatives are encouraging these employers to increase the hiring and retention of employees with disabilities. In the federal sector, Executive Order 13548 (EO 13548 2010), signed by President Obama in 2010, reaffirms the federal government's commitment to being a model employer for people with disabilities and requires that federal agencies reach hiring and retention targets for employees with disabilities. Specifically, EO 13458 aims to add 100,000 people with disabilities to the federal workforce by 2015 . For federal contractors, there are proposed regulations from the Office of Federal Contract Compliance Programs (OFCCP) that address the implementation of the disability non- 
discrimination and affirmative action requirements of Section 503 of the Rehabilitation Act (Office of the Federal Register 2011). The proposed OFCCP regulations include a recommendation that organizations holding federal contracts of $\$ 10,000$ or more achieve and maintain a workforce in which $7 \%$ of employees have disabilities. This has the potential to have a broad impact, as over 171,000 U.S. establishments are federal contractors (see the burden analysis in Office of the Federal Register 2011). These initiatives will require that both federal employers and federal contractors are increasingly able to be to measure their success in hiring and retaining individuals with disabilities.

\section{The Importance of Disability Self-Identification for Employers}

While some employers fear that knowledge of employees' disabilities could put them at risk for employment discrimination charges under the ADA, disclosure also carries significant benefits for employers as well as employees. These include the ability to make accommodations, to improve the workplace climate for individuals with disabilities, and to measure disability in order to comply with federal initiatives. This discussion sets the stage for the current study which aims to provide employers a better understanding of the disclosure decision from the perspective of individuals with disabilities and to provide actionable strategies for increasing disclosure.

Reasonable Accommodations Under the ADA, employers are required to provide employees with disabilities with reasonable accommodations when requested. Reasonable accommodations are adjustments or modifications that enable a person with a disability to perform the essential functions of a job efficiently and productively. However, an employer must first learn of the employee's disability and related functional limitations in order to make an accommodation. Studies have demonstrated that the majority of accommodations cost little or nothing and lead to improved employee productivity, attendance, attitudes and coworker interaction, as well as lower stress levels, improved coworker attitudes and increased overall organizational morale (Solovieva et al. 2011). These are all highly valued outcomes for employers working to create productive and positive workplaces.

Workplace Culture Research on employee engagement has highlighted that employees with disabilities tend to be less satisfied with their organization and its workplace climate and also perceive fewer opportunities for advancement than their non-disabled colleagues (Rutigliano and O'Connell 2013). Employees who perceive that their workplace has an inclusive climate feel higher levels of psychological empowerment on the job and higher levels of organizational support; these associations are even stronger for individuals with disabilities (Disability Case Study Research Consortium 2008). The perception of inclusion in the workplace in turn impacts employees' job satisfaction, commitment and productivity (Disability Case Study Research Consortium 2008). When employees feel comfortable self-disclosing a disability, this can serve as an informal indicator of the employer's success in achieving a supportive workplace culture. Further, seeing that their colleagues with disabilities are fairly treated can further build employee loyalty and commitment toward the organization.

Compliance with Initiatives The OFCCP regulations, as proposed, could require federal contractors to collect and report information on employees with disabilities across occupational categories annually. While contractors have been tracking this information based on gender and race/ethnicity representation across occupational categories for years, many have concerns about engaging in a similar process related to employees with disabilities. In particular, accurate tracking is contingent on employees and applicants with disabilities accurately self-identifying. Employers 
are justifiably concerned about these individuals' willingness to self-identify, as demonstrated by public comments in response to the OFCCP's proposed regulations by employer organizations such as the U.S. Chamber of Commerce, The Society for Human Resource Management, and The National Industry Liaison Group (Regulations.gov 2012). These organizations (and others) voiced a variety of concerns with the proposed rules, with each noting that individuals with qualifying disabilities may not wish to disclose, particularly if they do not need an accommodation, leading to poor quality data on disability representation within an organization.

The measurement of the success of EO 13458 in the federal sector hiring of people with disabilities also hinges on individuals with disabilities voluntarily self-identifying. A recent report from the Office of Personnel Management suggests that permanent employment of individuals with disabilities has been increasing since the Executive Order. In 2011, $11 \%$ of full-time permanent employees in the federal executive branch agencies were individuals with disabilities, including veterans with service connected disability ratings (U.S. Office of Personnel Management 2012). The federal government strives to be a model employer of people with disabilities, and appears to be having success in encouraging employees to disclose.

Measuring Disability in the Workplace Employers interested in increasing and capitalizing on the benefits of diversity (Kochan et al. 2003; Milliken and Martins 1996) and fostering inclusion in their workplace may want to track disability status, regardless of whether these federal initiatives apply to them or not. There are two specific ways in which employers might opt to gather information on disability in the workplace. First, employers may invite employees to self-disclose through applicant or staff surveys, providing an opportunity for individuals to request a reasonable accommodation under the ADA. While this disclosure information, along with any medical records, must be kept confidential and separate from employee personnel files, it would allow for the information to be linked to particular employees. This would then allow employers to develop a system to track individuals with disabilities like other groups of focus (e.g., women, minorities) and measure success in retention and advancement. An example of such an applicant or staff survey is the federal government's "Self-Identification of Disability" form (U.S. Office of Personnel Management 2010).

A second option is to provide employees an opportunity to disclose anonymously, perhaps on an engagement survey, without linking this information to any particular employee. This would allow employers to collect information on disability in the workplace generally and make comparisons to employees without disabilities. While it would not be possible to track individual employees with disabilities with the same level of detail as in the first option, this approach would help employers better understand disability within their workforce and improve organizational decision making about related policies and practices (e.g., leave policy development, wellness programming, etc.).

\section{Costs and Benefits of Self-Identification for Employees}

As noted above, employers have a growing list of reasons to encourage disability disclosure. Previous research has highlighted that there are both costs and benefits to individuals with nonvisible disabilities who choose to disclose their disabilities to their employers (Goldberg et al. 2005; Madaus 2008). Even employees who would directly and substantively benefit from an accommodation must weigh the workplace culture and their own personal beliefs with their need for accommodation (Baldridge and Veiga 2001).

Individuals with disabilities often do not disclose their disability out of concerns that it would result in lowered expectations, lack of respect, isolation from co-workers, a decrease in job responsibility, being passed over for promotion, or increased likelihood of termination (Brohan et al. 2012; Dalgin and Bellini 2008; Dalgin and Gilbride 2003; Madaus et al. 2002). Research 
supports many of these concerns, suggesting that disclosing disability can disadvantage job applicants (Dalgin and Gilbride 2003; Pearson et al. 2003) and existing employees (Balser 2000; Schur et al. 2009). Even in cases where concerns about disparate treatment are not present, individuals with disabilities may not disclose simply because they feel that their disability is irrelevant to job performance (Madaus 2008).

Despite these applicant and employee concerns, there are often benefits to disclosing. These include the aforementioned access to accommodations, the ability to explain behavior to a supervisor or coworkers or explain gaps in employment history (Allen and Carlson 2003; MacDonald-Wilson 2005), and increased support from coworkers, supervisors, or social networks (Allen and Carlson 2003; Brohan et al. 2012). Research suggests that workplace culture plays a particularly important role in disclosure decisions. A supportive workplace and coworkers are critical to discussing a disability in the workplace (Baldridge and Veiga 2001; Gignac and Cao 2009), as is demonstrating equitable treatment of individuals with disabilities in the workplace (Peters and Brown 2009).

\section{Current Study}

Given the current and possible future need for many employers to track the number of employees with disabilities and as well as desire among some employers to reap the benefits of creating a culture where individuals are comfortable disclosing, it is important for employers to understand the inherent trade-offs for individuals with disabilities in making the decision to disclose, and to ensure that the benefits of disclosing outweigh the costs for the individual. Toward this goal of informing employers about the perspectives of individuals with disabilities about the costs and benefits of disclosure, during the summer and fall of 2011, we collaborated with the American Association of People with Disabilities (AAPD) ${ }^{1}$ on the development and implementation of a survey on current critical issues around the employment of people with disabilities. In particular, this survey explored the motivations and barriers to disclosure, and asked individuals to describe a particular disclosure decision and experience. This paper discusses the implications for employers and provides recommendations for how employers can apply this information to make their workplaces more inclusive of individuals with disabilities and increase employee comfort in disclosing disabilities. This study goes beyond previous work focused on individuals with mental health or other non-visible disabilities to inform a broader understanding of the barriers and facilitators to disclosure for individuals with a wide range of disabilities.

This information is particularly relevant given the likelihood that demographic shifts and new initiatives will significantly increase existing disability hiring and retention efforts among employers. A management adage states, "You can't manage what you don't measure," and as the proportion of workers with disabilities grows, disability will increasingly be an issue that employers need to manage effectively.

\section{Method}

\section{Survey Development and Distribution}

The survey topics and specific questions were developed iteratively, and feedback about proposed survey items was solicited from a wide range of reviewers including people with disabilities,

\footnotetext{
${ }^{1}$ AAPD is a cross-disability membership organization that serves as the nation's largest disability rights organization; see www.aapd.com.
} 
employers, as well as individuals with expertise on employment and disability law, policy and workplace practices. A draft survey was piloted with 15 Employment and Disability Institute colleagues, both with and without disabilities, to ensure the language was clear and the questions were relevant to the target audience. The survey was revised based on feedback and the final version is available in the survey report (von Schrader et al. 2011). The survey includes closed and open-ended questions addressing disability disclosure in the workplace as well as leave as a reasonable accommodation and the use of job applicant screeners and credit checks during the pre-employment process. The latter topics are not discussed in this paper.

Distribution of the survey was conducted exclusively online, through two partner organizations: AAPD and a federal partner, the Substance Abuse and Mental Health Services Administration (SAMHSA). Participants were recruited via six distribution mechanisms: AAPD's Facebook and Twitter accounts; AAPD's general listserv and their Justice for All Newsletter (JFA); as well as SAMHSA's network listservs and an article in SAMHSA/Center for Mental Health Services (CMHS) Consumer Affairs E-News. The survey was conducted by the Survey Research Institute of Cornell University (SRI); SRI created six unique survey links, to allow us to track the recruitment source for each respondent.

A total of 780 participants completed the survey; and an additional 101 participants started the survey, answered at least one question, but did not complete it. Table 1 presents survey responses broken down by recruitment mechanism. We were interested in the efficacy of social media for recruiting participants for the survey, and found that recruiting via traditional listserv distribution resulted in greater response than our social media efforts. Although there were 103 surveys accessed via Facebook and 175 via Twitter, together these sources only resulted in 32 completed surveys, a "completed-to-touched" rate of just less than $12 \%$. More traditional methods of distributing the survey were found to be more successful. The AAPD outreach via the general listserv netted 133 completed surveys and a completed-to-touched rate of $65 \%$; while the JFA led to 366 completed surveys and a completed-to-touched rate of $71 \%$. SAMHSA's listserv distribution led to 1164 touched surveys and 212 completed responses; and the SAMHSA/CMHS newsletter led to 37 completed surveys.

It should be noted that the distribution of the surveys was not limited to only those on listservs or subscribers to the newsletters described above. The survey links were forwarded extensively; for example, we learned that the survey was promoted in the Northeast ADA Center newsletter and sent out to a National Federation of the Blind listserv.

Because we used a non-probability sampling strategy rather than randomly drawing a sample from a known population, our respondents are not a representative sample of any particular population, for example, people with disabilities or AAPD members. However, we do believe that the experiences that were collected from those who chose to respond reveal important insights about the costs and benefits of disclosure, as well as the decision-making process individuals engage in when contemplating disclosing a disability to an employer.

\section{Data Analysis}

The disclosure section of the survey was composed of a mix of closed and open-ended questions. For closed-ended items, response frequencies and comparisons among groups are presented. Chi-square tests were used to determine whether group differences are significant at the .05 level. In analyzing the main open-ended item responses, we conducted a thematic analysis (Braun and Clarke 2006). We began the analysis by thoroughly reading all of the responses to the item, and then developed a set of codes identifying features of interest in the data. We then grouped these coded responses into broader themes; which were further refined and quotations were selected from the text responses that represent these themes. In order to protect the confidentiality of 
Table 1 Surveys touched and completed by recruitment method

\begin{tabular}{|c|c|c|c|c|c|}
\hline & $\begin{array}{l}\text { Touched } \\
\text { surveys }\end{array}$ & $\begin{array}{l}\text { Total surveys } \\
\text { (including } \\
\text { incomplete) }\end{array}$ & $\begin{array}{l}\text { Completed } \\
\text { surveys }\end{array}$ & $\begin{array}{l}\text { Completed } \\
\text { to touched } \\
\text { rate }\end{array}$ & Survey advertised \\
\hline AAPD Facebook & 103 & 25 & 22 & $21 \%$ & Once per week for 4 weeks \\
\hline AAPD Twitter & 175 & 13 & 10 & $6 \%$ & Once per week for 4 weeks \\
\hline $\begin{array}{l}\text { AAPD general } \\
\text { listserv }\end{array}$ & 205 & 149 & 133 & $65 \%$ & $\begin{array}{l}\text { Once during last week of } \\
\text { survey }\end{array}$ \\
\hline $\begin{array}{l}\text { AAPD JFA } \\
\text { newsletter }\end{array}$ & 513 & 413 & 366 & $71 \%$ & $\begin{array}{l}\text { Once per week for } 3 \text { weeks } \\
\text { plus once as lead article and } \\
\text { subject line }\end{array}$ \\
\hline $\begin{array}{c}\text { SAMHSA } \\
\text { listservs }\end{array}$ & 1164 & 243 & 212 & $18 \%$ & $\begin{array}{l}\text { One email requesting } \\
\text { redistribution to listservs } \\
\text { of National Consumer } \\
\text { Technical Assistance Centers } \\
\text { and other employment-related } \\
\text { groups }\end{array}$ \\
\hline $\begin{array}{l}\text { SAMHSA/CMHS } \\
\text { newsletter }\end{array}$ & 49 & 38 & 37 & $76 \%$ & $\begin{array}{l}\text { Once in SAMHSA/CMHS } \\
\text { Consumer Affairs E-News } \\
\text { newsletter }\end{array}$ \\
\hline Total & 2209 & 881 & 780 & $35 \%$ & \\
\hline
\end{tabular}

respondents, we removed any identifying information from the quotes, and brackets or ellipses were inserted to show where text was suppressed. The open-ended items on the survey had a very high response rate. For example, on one item that was only asked of people with a disability who had disclosed in previous or most recent position $(N=470)$, over 370 individuals entered an open-ended response.

\section{Results}

In this section, we present descriptive statistics about the characteristics of survey respondents. We then present response frequencies from a series of items that offer insights into the barriers and facilitators of disclosure. Results are displayed for respondents with disabilities overall and by the subgroup characteristics of apparentness of disability, whether or not they disclosed in their current or most recent position, and if they were a disability service provider. We then discuss the results of the qualitative analysis of an open-ended item on addressing future disclosure decisions, providing further insight into the disclosure experiences of individuals with disabilities.

\section{Characteristics of Respondents}

The survey asked individuals to self-identify whether or not they had a disability; the majority of respondents identified as a person with a disability (599), while the rest (212) did not. In the survey instructions, a "person with a disability" was defined broadly to include (but not be limited to) individuals with a physical or cognitive disability, mental health condition, chronic health condition, vision or hearing impairment, or workplace injury or illness. We felt that these broader categories reflected those disabilities covered by the 
Americans with Disabilities Act Amendments Act of 2008 (ADAAA). We did not use the ADA definition of disability, ${ }^{2}$ which we felt might be difficult for respondents to interpret. In a separate question we asked individuals to identify specific conditions, using a list that was adapted from the Survey of Income and Program Participation (SIPP). Respondents with disabilities reported a variety of health conditions; the three most common were mental/emotional health conditions (50.0\%), back/spine problems (27.0\%), and arthritis/rheumatism (26.3\%). The large number of respondents having a mental/emotional health condition was expected, given the survey promotion through SAMHSA.

Analyses in this paper focus on individuals who self-identified as a person with a disability, and Table 2 presents characteristics of these respondents. Many of the respondents were disability service providers $(27.2 \%)$, likely an artifact of the survey distribution methods. Just over a third of respondents reported that their disability was very apparent to others, while nearly $40 \%$ indicated their disability was not apparent. Most respondents indicated that they had disclosed their disability in either their current or most recent job $(80.3 \%)$.

Approximately two-thirds of respondents were female and most were over 45 years old. Overall, respondents were highly educated; more than two-thirds had a college degree. More than four out of five identified their race as "white." Just over two-thirds of respondents with a disability were employed.

\section{Rating the Importance of Various Barriers and Facilitators to the Disclosure Decision}

The first section of the survey asked respondents to rate the importance of various factors in the decision to disclose (or not) on a scale from 1 - not at all important to 5-very important. The question asked: "Please indicate how important each factor would be to you, or to an employee/applicant with a disability, when deciding to [not] disclose a disability to an employer." Factors for these questions were developed based on the literature around the disclosure decision and in consultation with experts in disability employment. The facilitating factors focused on areas where an employer could make a change to improve the climate or culture for people with disabilities. In presenting the results of these ratings, we chose to dichotomize the ratings of importance and present the percent who indicated the factor was "very important."

Barriers to Self-Identification Table 3 presents factors which may pose a barrier to disclosure in order from highest to lowest percentage of respondents who indicated the factor as "very important." All barriers from the survey are included in the table. Among factors that may influence the decision to conceal a disability, the most highly rated responses among people with a disability were risk of being fired/not hired (73.0\% rated this as "very important"). This was followed by concern that the employer may focus on disability $(62.0 \%)$, the individual may lose health care benefits $(61.5 \%)$, have limited promotion opportunities $(61.1 \%)$, the supervisor may not be supportive (60.1\%), being treated differently by supervisor/co-workers $(57.8 \%)$ and being viewed differently by supervisor/co-workers (53.8\%). Overall fewer than one in three respondents rated a desire for privacy as a very important factor in the decision not to disclose; and fewer than half rated disability does not have an impact on the ability to perform the job as a very important factor in the decision not to disclose.

\footnotetext{
${ }^{2}$ The ADA defines disability as "(A) a physical or mental impairment that substantially limits one or more major life activities of such individual; (B) a record of such an impairment; or (C) being regarded as having such an impairment". The ADA Amendments Act of 2008 broadened the interpretation of disability that had narrowed as a result of Supreme Court decisions, making it easier for an individual to establish that he or she has a disability under the ADA definition.
} 
Table 2 Characteristics of survey respondents

\begin{tabular}{|c|c|}
\hline & $\begin{array}{l}\text { Percent of } \\
\text { respondents with a } \\
\text { disability }(N=599)\end{array}$ \\
\hline Disability service provider & 27.2 \\
\hline Very apparent disability & 34.8 \\
\hline Somewhat apparent disability & 26.7 \\
\hline Not apparent & 38.5 \\
\hline $\begin{array}{l}\text { Disclosed disability in current or most } \\
\text { recent job (only asked of individuals who } \\
\text { had ever worked, } N=589 \text { ) }\end{array}$ & 80.3 \\
\hline Female & 65.9 \\
\hline 18-24 years old & 1.8 \\
\hline 25-34 years old & 13.4 \\
\hline $35-44$ years old & 17.8 \\
\hline $45-54$ years old & 30.7 \\
\hline 55-64 years old & 29.5 \\
\hline more than 65 years old & 6.8 \\
\hline Less than high school & 1.1 \\
\hline High school graduate or GED certificate & 4.0 \\
\hline Technical, trade, or vocational school & 3.5 \\
\hline Some college, but less than a 4-year degree & 24.0 \\
\hline College graduate or higher & 67.4 \\
\hline White & 84.2 \\
\hline Black/African American & 8.3 \\
\hline Asian & 1.6 \\
\hline American Indian or Alaska Native & 5.7 \\
\hline Latino/Hispanic & 3.0 \\
\hline Other Race & 3.1 \\
\hline Currently employed & 67.4 \\
\hline Mental/emotional health conditions & 50.0 \\
\hline Arthritis/rheumatism & 26.3 \\
\hline Back/spine problems & 27.0 \\
\hline
\end{tabular}

In order to further understand the relationship between respondent characteristics and ratings of factor importance, we conducted analyses grouping respondents based on the following factors: (1) how apparent their disability is; (2) whether they disclosed in their most recent position (only asked of individuals who have worked); and (3) whether they are employed as a disability service provider. Those with a less apparent disability were more likely to rate the above factors as very important, as compared with those with a very apparent disability. Significant differences were found for: concern about being fired or not being hired (77.4\% among those with a less apparent disability compared to $65.2 \%$ for those with a very apparent disability), losing health benefits (64.8 \% vs. $54.9 \%$ ), losing promotion opportunities ( $64.1 \%$ vs. $55.7 \%)$, lack of supervisor support/understanding $(65.8 \% \mathrm{vs}$. $49.0 \%$ ), being treated differently (63.7 \% vs. $46.3 \%)$, being viewed differently (61.2 \% vs. $39.7 \%)$ and a desire to keep the disability private (31.0\% vs. $21.6 \%$ ).

Those who did not disclose in their most recent position rated many of the above factors as more important than did respondents who had disclosed. In particular, concerns about being treated differently (67.5\% vs. $55.4 \%)$ and viewed differently (62.6\% vs. $51.3 \%)$. They were also 
far more likely to rate as very important the desire to keep the disability private ( $42.6 \%$ vs. $24.3 \%$ ) and the belief that their disability is not related to the job (56.5\% vs. $41.8 \%)$. Finally, we compared those employed as a disability service provider to others; as we believe that those in the disability sector may have a different perspective on disability disclosure, as disability is a focus in their workplaces. As expected, disability service providers had lower ratings on some of the factors, with significantly lower ratings on concerns about: employer focusing more on the disability (54.9\% vs. $64.6 \%$ ), losing health benefits (vs. $53.1 \%$ vs. $64.7 \%$ ), and promotion opportunities will be limited (49.7\% vs. $65.4 \%$ ).

A few other factors were added by respondents in the open-ended opportunity to rate additional factors; most were concerns that fit into the factors listed in Table 3. Many respondents highlighted concern over being treated differently, particularly emphasizing a concern about coworker attitudes and fear of bullying by other employees - e.g., "Once the disability becomes known the workplace becomes 'unfriendly"'. Others had concerns that employers might not be knowledgeable of the laws protecting people with disability from workplace discrimination.

Overcoming Barriers to Self-Identification We also examined a set of workplace factors that may encourage disclosure, with a focus on areas that employers may target to improve inclusiveness of their organization. In addition to these organizational factors, we included the need for accommodation, an individual factor that is often the primary reason for disclosure. Table 4 presents these all facilitating factors ordered from highest to lowest percentage of respondents who indicated the factor as "very important" in their decision to disclose.

For people with a disability the most important factors were need for an accommodation (68.2\% rated this factor as very important) and having a supportive supervisor relationship $(63.5 \%)$. However the context of the workplace was also important. Individuals with disabilities rated highly knowing employer has made concerted efforts to create disability/friendly workplace (56.8\%), knowing that the employer was actively recruiting people with disabilities (50.5\%), knowing of other employees who had disclosed and were successful (49.9\%), and disability included in the diversity statement (48.9\%). Many thought it was very important to know that disclosure would lead to new opportunities for promotion or training $(40.7 \%)$, to see a message of disability inclusiveness on the company's promotional materials (38.0\%) and recruitment materials (37.8\%), or to see an employee with a disability at recruitment events $(32.4 \%)$. Just over a quarter felt it was very important that the employer had a disability-focused employee resource group (ERG) $(26.1 \%)$.

There were differences across subgroups with relation to which factors were rated as "very important" to encouraging disclosure. Individuals with a less apparent disability were more likely than those with very apparent disabilities to rate as "very important" a belief that disclosure would lead to new training opportunities (44.8 \% vs. $33.5 \%$ ) and the presence of a disability ERG $(29.7 \%$ vs. $19.3 \%$ ). There were also differences between those who did and did not disclose in their current or most recent position. Those who did disclose were more likely to rate the need for an accommodation as a very important factor ( $69.9 \%$ vs. $60.3 \%)$, but were less likely to rate having a statement on recruitment material (36.1\% vs. $46.1 \%)$, having an employee with disability at job fairs (30.7 vs. $40.4 \%$ ) and having an ERG (23.3 vs. $35.7 \%$ ) as "very important." Finally, there were also differences between people with disabilities who were working as disability service providers and those who were not. In particular, those not in disability services were more likely to rate new opportunities for promotion or training (43.8 \% vs. $32.7 \%$ ) and the presence of a disability ERG ( $28.5 \%$ vs. $19.8 \%$ ) as "very important". Those not working in disability services and those with a less visible disability rated more factors as "very important" than did other subgroups.

A variety of other factors were added by respondents who had the opportunity to add and rate two additional open-ended factors. Some of the factors that were commonly mentioned as 


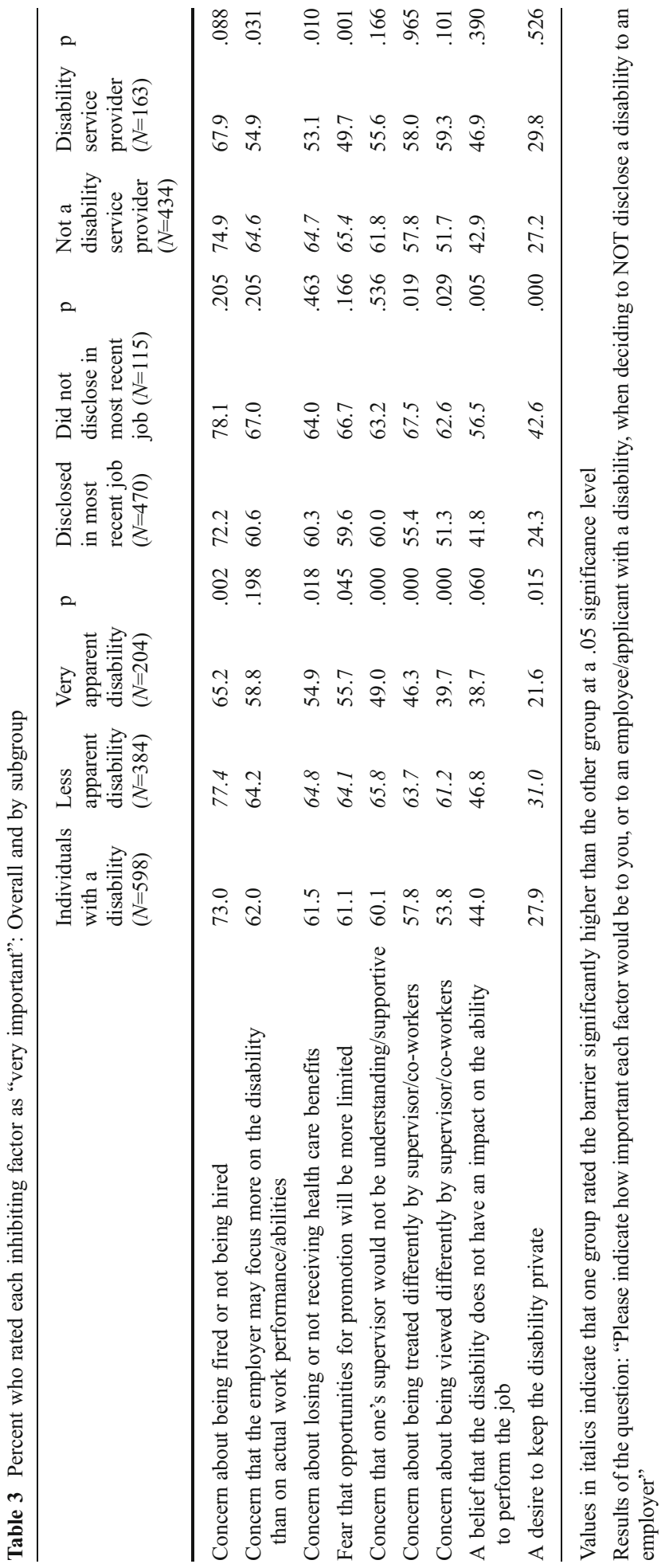




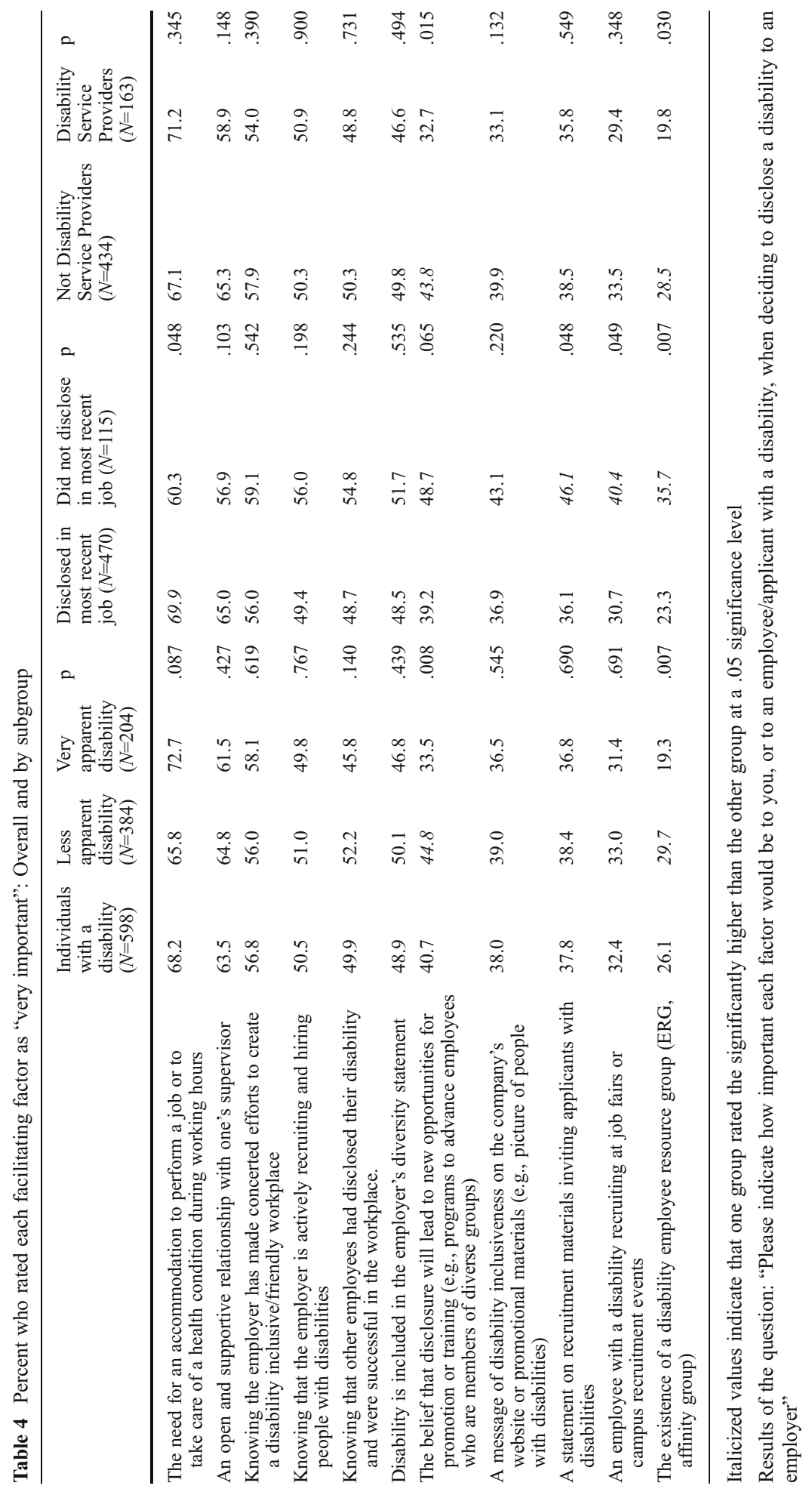


important in making the decisions to disclose included: flexible work opportunities (e.g., parttime, work from home, flexible schedule, flexible leave policy), disability awareness training offered to all employees in the workplace, HR personnel who are familiar with disability and accommodations, and a fair system for submitting grievances. Some respondents noted the importance of having accessible websites and facilities, supporting diversity more generally (e.g., racial diversity) and supporting and participating in community awareness event/activities (e.g., Special Olympics) to their disclosure decision.

\section{Characteristics of a Recent Disclosure Decision}

Overall, around $80 \%$ of respondents disclosed their disability in their current or most recent job. Individuals with "very apparent" disabilities were more likely to have disclosed their disability at their current or most recent job (89\%), than were those with disabilities that were less apparent $(77 \%)$. Individuals working as a disability service provider were more likely to disclose $(86 \%)$ than those who were not disability service providers $(78 \%)$.

The survey asked individuals with a disability additional questions about their disclosure experience at their current or most recent job, including inquiries about the timing and the perceived consequences of the disclosure. A selection of findings from these questions is presented in Table 5. Among individuals with very apparent disabilities who had disclosed their disability in their current or most recent job, $51 \%$ disclosed during the recruitment process, $34 \%$ during the interview process, and $15 \%$ after being hired. Among individuals with disabilities with less apparent disabilities, fewer disclosed during recruitment (39\%) or the interview process $(25 \%)$, while more individuals waited until after being hired to disclose their disabilities (36\%). Individuals who were disability service providers disclosed earlier in the employment process; $52 \%$ during recruitment, $26 \%$ during the interview process, and $22 \%$ after being hired.

Among those who disclosed, fewer than $10 \%$ rated their immediate disability disclosure experience as negative; while nearly a quarter of respondents rated the longer term consequences of the disability disclosure experience as negative $(24 \%)$. There was a significant difference between those working as disability service providers and those who were not, for example disability service providers reported lower rates of negative long-term consequences $(15.3 \%)$, compared to those who were not disability service provider $(28.1 \%)$.

\section{What Would Make You Disclose/Not Disclose in the Future?}

Respondents who disclosed in their current or most recent position were asked further whether they would disclose if presented with a similar situation in the future. Most $(62.5 \%)$ said they would disclose, $31.8 \%$ said "maybe, it depends," while the remainder said they would not disclose (5.7\%). An open ended question followed asking the respondents to "Please explain why you would or would not disclose in the future." Responses from 370 respondents (out of 470 who had disclosed) were included in the analysis, providing further description and understanding of the barriers and facilitators to disclosure. We focused our analysis on responses where individuals described factors that influenced their disclosure decision. Many respondents answered the question by describing a disability disclosure experience in their past that would influence their future decisions.

We identified four major themes and six additional subthemes in these responses: (1) balancing the need for accommodation with the timing of disclosure, (2) importance of assessing the workplace climate and supervisor relationship prior to disclosure, (3) disability identity (subthemes: desire to be accepted for "who I am"; honesty reduces stress; and desire to be an example of disability success), and (4) concern about disparate treatment upon disclosure 
Table 5 Characteristics of respondents' disclosures decisions in their current or most recent job, overall and by subgroup

\begin{tabular}{|c|c|c|c|c|c|c|c|}
\hline & $\begin{array}{l}\text { Individuals } \\
\text { with a } \\
\text { disability } \\
(N=599)\end{array}$ & $\begin{array}{l}\text { Less } \\
\text { apparent } \\
\text { disability } \\
(N=384)\end{array}$ & $\begin{array}{l}\text { Very } \\
\text { apparent } \\
\text { disability } \\
(N=204)\end{array}$ & $p$ & $\begin{array}{l}\text { Not a } \\
\text { disability } \\
\text { service } \\
\text { provider } \\
(N=436)\end{array}$ & $\begin{array}{l}\text { Disability } \\
\text { service } \\
\text { provider } \\
(N=163)\end{array}$ & $p$ \\
\hline$\%$ who disclosed & 80.3 & 76.6 & 88.9 & .001 & 78.1 & 86.3 & .027 \\
\hline \multicolumn{8}{|c|}{ Among those who disclosed } \\
\hline \multicolumn{8}{|c|}{ First disclosed disability } \\
\hline $\begin{array}{l}\text { During the } \\
\text { recruitment } \\
\text { process }\end{array}$ & 43.4 & 39.3 & 50.6 & .000 & 39.8 & 52.2 & .033 \\
\hline $\begin{array}{c}\text { During the } \\
\text { interview } \\
\text { process }\end{array}$ & 28.2 & 24.9 & 34.1 & & 29.1 & 26.1 & \\
\hline $\begin{array}{l}\text { After being } \\
\text { hired }\end{array}$ & 28.4 & 35.8 & 15.3 & & 31.2 & 21.7 & \\
\hline \multicolumn{8}{|c|}{ Was your immediate disability disclosure experience... } \\
\hline Negative & 9.2 & 10.6 & 6.9 & .365 & 10.9 & 5.1 & .000 \\
\hline Neutral & 38.3 & 36.5 & 40.5 & & 43.6 & 25.4 & \\
\hline Positive & 52.6 & 52.9 & 52.6 & & 45.5 & 69.6 & \\
\hline \multicolumn{8}{|c|}{ Was your longer-term disability disclosure experience... } \\
\hline Negative & 24.4 & 26.9 & 19.8 & .130 & 28.1 & 15.3 & .003 \\
\hline Neutral & 34.3 & 31.4 & 39.0 & & 36.1 & 29.9 & \\
\hline Positive & 41.4 & 41.7 & 41.3 & & 35.8 & 54.7 & \\
\hline
\end{tabular}

Italicized values indicate a significant difference between groups at a .05 significance level

(subthemes: concern over firing/not being hired; loss of promotion opportunity; and workplace harassment and bullying). The following sections highlight these themes and subthemes and present representative quotes to further clarify each of the themes.

Balancing the Need for Accommodation with Timing of Disclosure Not surprisingly, accommodation was a critical issue in the decision to disclose and many respondents described their specific needs for accommodation in the workplace. While an individual may need an accommodation, many respondents expressed concern that disclosing too early in the hiring process might impact their chance of getting a job. The timing of the disclosure was important to many respondents, who reported that they preferred to wait until hired to disclose: "I tended to let employers see my work before letting them know that I am hard-of-hearing." Although many respondents had an obvious disability and had no choice in disclosure, some noted that they disclosed only their visible disability and did not disclose other, less visible disabilities, e.g., "I have an apparent disability therefore I can't hide it. In addition, I have an invisible disability and I don't disclose the circumstances of that part of my disability until it is time to discuss accommodations, as I need different accommodations for my invisible disability."

Assessing the Supervisor and Environment Respondents noted that the supervisor as well as the environment of the company was important in their decision to disclose, e.g., "I would be 
less likely to disclose if I felt that my employer would not be understanding," "My boss respected me and understood the difficulties I have. I have concerns about a new employer being as understanding and supportive as my last boss," and "It depends on the responsiveness of co-workers, supervisors, and general work environment." Several noted that a company simply having progressive policies is not enough; they need to observe how employees with disabilities are treated in the workplace before making a disclosure decision, e.g., "I would be wary of disclosing until I saw how the employer actually treated employees with mental health issues, not just their stated policy. There would have to be trust in my supervisors and colleagues," and "company policies are worthless if discriminatory behaviors are not curbed and the disabled are seen as too unreliable and costly."

Disability as Identity Several respondents noted that "disability is part of who I am." Some of these respondents said that they wanted to disclose because they wanted to gauge whether an employer would accept them for who they are. If individuals believed that they would not be accepted, some reported that they would look elsewhere for employment - "I won't work for someone who does not accept me for who I am!" or "I prefer to disclose my disability, then I would be able to detect any body languages, reactions, or type of vibe by the interviewers or supervisors. It gave me the idea of what kind of environment that I would be risking myself if I got hired." Others noted that being honest was important to them, and that this straightforward approach makes later interaction with the employer less stressful, e.g., "Disclosing makes life simpler - I am who I am and I am a person with a disability. Trying to cover that or pretend takes way too much energy." Several respondents mentioned that they felt an obligation (or desire) to disclose to educate others, both employers and coworkers, that individuals with disabilities can be productive members of the workforce, e.g., "I ... am proud to show that people with 'disabilities' are competent, valued employees."

Disclosure Leads to Disparate Treatment Many respondents noted that there was discrimination ("ignorance and fear") in the workplace against individuals with known disabilities, "Discrimination occurs right from the moment of disclosure. Although there are efforts to end this discrimination, it remains and companies just try to cover it up." The most common reasons for not disclosing were fear of losing out on employment opportunities, that is, not being hired, being fired or not being promoted. Many individuals who said they would not disclose expressed concerns related to not being hired or being fired, e.g., "Disability is still being treated like acute disease. Until these change, there is still too high a risk of losing one's job if you disclose." Several disability service providers noted that they felt comfortable disclosing in their current position but would not disclose in a non-disability related job, e.g., "I work in an office where all of us are disabled and it is a requirement to have a disability to work here. However if I had to work in a 'regular' atmosphere I would never disclose my disability due to the fear of being singled out."

Many respondents indicated a concern that opportunities for advancement might be limited if they disclosed and described their own experiences and perceptions related to being passed over for promotions, e.g., "I feel that I did not receive a recent promotion because of my disability and the belief that I am not able to do the job when I fit all of the requirements for the position" and "I found that having to disclose my disability with the last company I worked at, there wasn't a direct negative response. However, I did get the feeling that I was held back from promotional opportunities, when I was fully capable to handle the responsibilities."

Many respondents discussed being subjected to workplace harassment and bullying as a result of their disability disclosure, e.g., "I had a particularly bad experience with a supervisor who was attempting to force me to quit the company-This included making various disparaging statements in private to me (such as: that I was a 'cripple', broken person, dysfunctional, useless, etc.), while 
making unreasonable demands/work assignments, and various attempts to get me in trouble with others," "I was harassed daily, denied further training and eventually fired", and "In the beginning [my employer] was supportive, but as the years went on I was bullied, harassed, belittled, written up and eventually fired. I was screamed at, called lazy, treated extremely cruel."

Overall, the open-ended responses provided a helpful window into the disclosure experiences of people with disabilities in the workplace. Most respondents had a positive or at least neutral disclosure experience at their current or most recent position, but not all. These previous experiences played a key role in their future plans for disclosure. Many of the comments highlighted the importance of workplace climate and culture in making their decision.

\section{Discussion}

The Rehabilitation Act of 1973 and the ADA of 1990 have been in place for decades and have built awareness among the employer community about disability non-discrimination. However, the implementation of these laws has not led to a significant reduction in the employment gap between individuals with and without disabilities. There is now a confluence of factors putting disability employment in the spotlight. With an aging workforce and returning veterans, many employers are experiencing an increase in disability in their workforce. At the same time, federal employers and contractors are facing new initiatives pushing them to hire and retain individuals with disabilities. It is an important time for employers to consider how to effectively measure and manage disability in their workforce.

Creating an environment in which employees feel encouraged to disclose that they have disability is the key to accurately measuring and responding to disability in the workplace. In designing strategies to encourage self-disclosure, it is critical that employers first understand the experiences and perceptions of individuals with disabilities. Ultimately, this survey revealed that individuals' decision to disclose are often complex and fraught with personal and environmental considerations; and there are a multitude of actions employers can take to either inhibit or encourage this disclosure. In this discussion we highlight some key findings from the survey and suggest ways employers may effectively communicate to employees that the benefits of disclosure will outweigh possible costs for the individual.

\section{Key Findings and Suggestions for Employers}

Many respondents expressed concerns about the potential consequences of disclosure; this included fears about disparate treatment in hiring, workplace interactions, and advancement. Concerns about being treated or viewed differently were especially salient for individuals with non-apparent disabilities and those who ultimately chose not to disclose. Despite these concerns, the vast majority ( $80 \%$ ) of respondents did opt to disclose their disability in their current or most recent position for reasons that ranged from a need for accommodation to a desire for honesty and openness. Of those who disclosed, nearly a quarter reported that they did, in fact, experience long term negative consequences related to their disclosure. These findings reinforce previous studies that have found that disability disclosure can have a very real impact on the workplace experiences of individuals with disabilities (Brohan et al. 2012).

Our findings suggest that employers should educate supervisors and employees more generally about the negative consequences of holding stereotypes about people with disabilities, and even more importantly, about the inappropriateness and the possible legal consequences of treating people with disabilities as less valued members of a workplace. Disability awareness training for all employees can help to decrease stereotypes and 
misunderstandings about the capabilities of individuals with disabilities, as well as offer concrete suggestions for positively interacting with people with disabilities.

This survey also revealed a wide range of other employer behaviors which may encourage disability disclosure and may subsequently reduce negative consequences of that disclosure. Other studies have highlighted the importance of co-worker and supervisor relationships to the integration and social inclusion of employees with disabilities into the workplace (Kulkarni and Lengnick-Hall 2011). Similarly, we found that an employee's relationship with his or her supervisor was rated most highly among employer-related factors encouraging disclosure. Individuals were more likely to disclose disabilities if they had a positive and supportive relationship with their supervisors. This suggests that organizations may be able to encourage disclosure by fostering positive supervisor-employee relationships. Management and disability awareness training (e.g., building skills in listening, conflict resolution, etiquette, and providing accommodation) are ways to help increase supervisors' comfort in discussing what can, at times, be a sensitive topic.

Workplace culture and an employer's perceived commitment to disability inclusion were also important factors in the decision to disclose. There are a variety of ways in which employers can communicate this commitment, such as: including disability in the organization's diversity statement; including people with apparent disabilities in the company's promotional material; and encouraging applicants with disabilities on recruitment materials. Each of these organizational practices can build employee trust in the organization's commitment to disability inclusion and be a factor in an individual's decision to disclose a disability. Many respondents also noted that seeing an individual with a disability who had succeeded in the workplace was an important factor in their own decision to disclose. By promoting the successes of workers with disabilities, an employer may further cultivate a culture that encourages disclosure. In our analyses of open-ended responses, several respondents highlighted their interest in disclosing and serving as an example of successful and valued employees with disabilities in their organization's workforce. In addition, the presence of a disability-focused employee resource group is also a visible sign of organizational commitment and was a particularly important factor in the disclosure decision for individuals with a less apparent disability.

Many respondents noted the importance of believing that they would not be held back on the career ladder because of their disability disclosure. Individuals with a less apparent disability and those not employed as a disability service provider were more likely to indicate that new opportunities for promotion or training were very important in their decision to disclose. Organizations should consider including individuals with disabilities in mentoring programs or other training opportunities that have been used to increase the presence of other historically underrepresented groups (e.g., women and racial/ethnic minorities) in management.

\section{Conclusion}

As employers gather experiences with disabilities acquired by an aging workforce and returning veterans with disabilities, and begin to respond to the requirements of federal initiatives, it will become increasingly important for organizations to develop proactive policies to increase disability inclusion and thereby encourage disclosure. These survey findings offer an opportunity for employers to hear directly from individuals with disabilities about the impact of workplace policies and practices on individuals' disability disclosure decisions. Creating a disability inclusive workplace, actively recruiting and hiring individuals with disabilities, and including disability in the organization's diversity statement are 
just a few of the practices that respondents felt were very important when making the decision to disclose to an employer.

While the decision to disclose a disability will remain highly personal, it is clear that there are a wide range of actions employers can take to build an inclusive workplace and develop trust with employees. As employers begin collecting disability data from employees for internal or compliance purposes, they must be clear about the purpose of the information, and whether it is for anonymous monitoring or for helping a given individual with accommodation supports. It is by building a strong and inclusive workplace, with clear communication about the purpose of disability data collection, that employers will be able to respond to federal mandates and simultaneously realize the benefits of a workplace that fully includes individuals with disabilities.

Open Access This article is distributed under the terms of the Creative Commons Attribution License which permits any use, distribution, and reproduction in any medium, provided the original author(s) and the source are credited.

\section{References}

Americans with Disabilities Act of 1990, Pub. L. No. 101-336, § 2, 104 Stat. 328 (1991).

Americans with Disabilities Act of 1990, as Amended (2009). 42 U.S.C. $§ 12101$ et seq.

Allen, S., \& Carlson, G. (2003). To conceal or disclose a disabling condition? A dilemma of employment transition. Journal of Vocational Rehabilitation, 19, 19-30.

Baldridge, D. C., \& Veiga, J. F. (2001). Toward a greater understanding of the willingness to request an accommodation: can requesters' beliefs disable the Americans with disabilities act? The Academy of Management Review, 26(1), 85-99.

Balser, D. B. (2000). Perceptions of on-the-job discrimination and employees with disabilities. Employee Responsiblities and Rights Journal, 12(4), 179-197.

Bjelland, M., Burkhauser, R., von Schrader, S., \& Houtenville, A. (2011). 2010 Progress report on the economic well-being of working-age people with disabilities. Ithaca: Cornell University.

Braun, V., \& Clarke, V. (2006). Using thematic analysis in psychology. Qualitative Research in Psychology, $3(2), 77-101$.

Brohan, E., Henderson, C., Wheat, K., Malcolm, E., Clement, S., Barley, E. A., et al. (2012). Systematic review of beliefs, behaviours and influencing factors associated with disclosure of a mental health problem in the workplace. BMC Psychiatry, 12(11), 1-14.

Bruyère, S. M., Erickson, W., \& Van Looy, S. (2000). HR's role in managing disability in the workplace. Employment Relations Today, 27(3), 47-66.

Dalgin, R. S., \& Bellini, J. (2008). Invisible disability disclosure in an employment interview: impact on employers' hiring decisions and views of employability. Rehabilitation Counseling Bulletin, $52(1), 6-15$.

Dalgin, R. S., \& Gilbride, D. (2003). Perspectives of people with psychiatric disabilities on employment disclosure. Psychiatric Rehabilitation Journal, 26(3), 306-310.

Disability Case Study Research Consortium. (2008). Conducting and benchmarking inclusive employment policies, practices, and culture: Final report. Syracuse: Burton Blatt Institute, Syracuse University.

Domzal, C., Houtenville, A., \& Sharma, R. (2008). Survey of employer perspectives on the employment of people with disabilities: Technical report. McLean: CESSI.

Erickson, W., Lee, C., \& von Schrader, S. (2012). 2010 Disability status report: United States. Ithaca: Cornell University.

Gignac, M. A. M., \& Cao, X. S. (2009). "Should I tell my employer and coworkers I have arthritis?" A longitudinal examination of self-disclosure in the work place. Arthritis \& Rheumatism-Arthritis Care \& Research, 61(12), 1753-1761.

Goldberg, S. G., Killeen, M. B., \& O’Day, B. (2005). The disclosure conundrum: how people with psychiatric disabilities navigate employment. Psychology, Public Policy, and Law, 11(3), 463-500.

He, W., Sengupta, M., Velkoff, V. A., \& DeBarros, K. A. (2005). 65+ in the United States: 2005; U.S. Department of the Census: Current population reports. Washington: U.S. Government Printing Office.

Houtenville, A. J., Potamites, E., Erickson, W. A., \& Ruiz-Quintanilla, S. A. (2009). Disability prevalence and demographics. In A. J. Houtenville, D. C. Stapleton, R. R. Weathers II, \& R. V. Burkhauser (Eds.), Counting working age people with disabilities (pp. 69-99). Kalamazoo: W.E. Upjohn Institute for Employment Research. 
Kessler/NOD. (2010). The ADA, 20 years later: Kessler Foundation/NOD survey of Americans with disabilities. New York: Harris Interactive.

Kochan, T., Bezrukova, K., Ely, R., Jackson, S., Joshi, A., Jehn, K., et al. (2003). The effects of diversity on business performance: report of the diversity research network. Human Resource Management, 42(1), 3-21.

Kulkarni, M., \& Lengnick-Hall, M. (2011). Socialization of people with disabilities in the workplace. Human Resource Managment, 50(4), 521-540.

Lengnick-Hall, M., Gaunt, P., \& Kulkarni, M. (2008). Overlooked and underutilized: people with disabilities are an untapped human resource. Human Resource Management, 47(2), 255-273.

MacDonald-Wilson, L. K. (2005). Managing disclosure of psychiatric disabilities to employers. Journal of Applied Rehabilitation Counseling, 36(4), 11.

Madaus, J. W. (2008). Employment self-disclosure rates and rationales of university graduates with learning disabilities. Journal of Learning Disabilities, 41(4), 291-299.

Madaus, J. W., Foley, T. E., McGuire, J. M., \& Ruban, L. M. (2002). Employment self-disclosure of postsecondary graduates with learning disabilities: rates and rationales. Journal of Learning Disabilities, 35(4), 364.

Milliken, F. J., \& Martins, L. L. (1996). Searching for common threads: understanding the multiple effects of diversity in organizational groups. The Academy of Management Review, 21(2), 402.

Office of the Federal Register. (2011). Affirmative action and non-discrimination obligations of contractors and subcontractors regarding individuals with disabilities, proposed rule. Federal Register, 76(237), 77056-77076.

Pearson, V., Ip, F., Hui, H., Yip, N., Ho, K. K., \& Lo, E. (2003). To tell or not to tell: disability disclosure and job application outcomes. Journal of Rehabilitation, 69(4), 35.

Peters, H., \& Brown, T. C. (2009). Mental illness at work: an assessment of co-worker reactions. Canadian Journal of Administrative Sciences, 26(1), 38-53.

Ramchand, R., Karney, B. R., Osilla, K. C., Burns, R. M., \& Caldarone, L. B. (2008). Prevalence of PTSD, depression, and TBI among returning servicemembers. In T. Tanielan \& L. Jaycox (Eds.), Invisible wounds of war: Psychological and cognitive injuries, their consequences, and services to assist recovery (pp. 35-85). Santa Monica: Rand Center for Military Health Policy.

Regulations.gov (2012). Comments on OFCCP-2010-0001. Washington, D.C.: U.S. Environmental Protection Agency eRulemaking Program. http://www.regulations.gov/\#! searchResults; dct=PS;rpp=25; so=DESC;sb=postedDate;po=0;dktid=OFCCP-2010-0001. Accessed 7 June 2013.

Rehabilitation Act of 1973, as Amended, 29 U.S.C. $\S 701$.

Richardson, L. K., Frueh, B. C., \& Acierno, R. (2011). Prevalence estimates of combat-related PTSD: a critical review. The Australian and New Zealand Journal of Psychiatry, 44(1), 4-19.

Rutigliano, P., \& O’Connell, M. (2013). Employees with disabilities the forgotten diversity segment: Tracking trends. New York: Sirota/NOD.

Robert, P. M., \& Harlan, S. L. (2006). Mechanisms of disability discrimination in large bureaucratic organizations: ascriptive inequalities in the workplace. The Sociological Quarterly, 47(4), 32p.

Rudstam, H., Strobel Gower, W., \& Cook, L. (2012). Beyond yellow ribbons: are employers prepared to hire, accommodate and retain returning veterans with disabilities? Journal of Vocational Rehabilitation, 36, 87-95.

Schur, L., Kruse, D., Blasi, J., \& Blanck, P. (2009). Is disability disabling in all workplaces? Workplace disparities and corporate culture. Industrial Relations, 48(3), 381-410.

Solovieva, T. I., Dowler, D. L., \& Walls, R. T. (2011). Employer benefits from making workplace accommodations. Disability and Health Journal, 4(1), 39-45.

Toossi, M. (2012). Labor force projections to 2020: a more slowly growing workforce. Monthly Laboer Review, 135, 43-64.

U.S. Census Bureau. (2011). American FactFinder, Table S1811: Selected economic characteristics for the civilian non-institutionalized population by disability status. http://factfinder.census.gov/home/saff/ main.html?_la ng=en. Accessed 7 June 2013.

U.S. Office of Personnel Management. (2010). Standard Form (SF) 256-Self-Identification of Disability. Washington, D.C.: OPM.gov. http://www.opm.gov/forms/pdf_fill/sf256.pdf. Accessed 7 June 2013.

U.S. Office of Personnel Management. (2012). Report on the employment of individuals with disabilities in the Federal Executive Branch, FY 2011. Washington: OPM.

von Schrader, S., Malzer, V., Erickson, W., \& Bruyere, S. M. (2011). Emerging employment issues for people with disabilities: Disability disclosure, leave as a reasonable accommodation, use of job applicant screeners. Ithaca: Cornell University.

Weathers, R. R., II, \& Wittenburg, D. C. (2009). Employment. In J. Houtenville, D. C. Andrew, R. R. Stapleton, I. I. Weathers, V. Burkhauser, \& Richard (Eds.), Counting working age people with disabilties (pp. 101-143). Kalamazoo: W.E. Upjohn Institute for Employment Research. 